\title{
The Openness-calibration hypothesis is
}

\author{
David M.G. Lewis ${ }^{\mathrm{a}, *}$, Laith Al-Shawaf ${ }^{\mathrm{b}}$, Cansu Yilmaz ${ }^{\mathrm{a}}$ \\ a Bilkent University, Turkey \\ ${ }^{\mathrm{b}}$ The University of Texas at Austin, USA
}

\section{A R T I C L E I N F O}

Article history:

Received 30 April 2014

Received in revised form 7 December 2014

Accepted 17 December 2014

Available online 13 January 2015

\section{Keywords:}

Evolutionary psychology

Personality

Individual differences

Openness to Experience

SOI

Attractiveness

Mating strategy

Physical attractiveness

\begin{abstract}
A B S T R A C T
The current study tested the hypotheses that (1) psychological adaptations calibrate Openness to Experience to facilitate or deter pursuit of short-term mating, and (2) this calibration varies as a function of mating strategy, physical attractiveness, and sex-individual differences that shift the costs and benefits of alternative personality strategies. Participants completed a personality inventory before and after reading vignettes describing mating opportunities of different durations (short- and long-term) with individuals of differing levels of attractiveness. Among study findings, participants presented with short-term mating opportunities with individuals of average attractiveness exhibited down-regulated Openness relative to those presented with highly attractive mates. Moreover, these effects varied as a function of the interaction between participants' sex, mating strategy, and attractiveness. These findings are consistent with the hypothesis that evolved psychological mechanisms adaptively calibrate Openness levels in response to short-term mating opportunities. More broadly, they highlight the heuristic value of an evolutionary framework for the study of personality and individual differences.
\end{abstract}

(C) 2014 Elsevier Ltd. All rights reserved.

\section{Introduction}

Personality psychology provides a rich body of empirical research and a well-established descriptive taxonomy, but does not offer a generative framework for predicting the conditions that evoke the development of personality traits. An evolutionary psychological approach, which posits that many cognitions, emotions, and behaviors are produced by psychological adaptations designed to solve survival- and reproduction-related challenges (Buss, 1995), may provide a predictive theoretical framework for identifying the processes responsible for individual differences in personality and the contexts in which they emerge.

\subsection{Personality: cost-benefit tradeoffs}

Within an adaptationist perspective, personality traits can be conceptualized as functional strategies to solve survival- and reproduction-related challenges recurrent during our species' evolution (Buss, 2009). This framework can be applied through a theory-driven, "top-down" approach (Buss, 1995): a researcher (1) identifies a distinct adaptive challenge, (2) articulates the behaviors that could have helped solve the challenge and the psy-

\footnotetext{
This article is a Special issue article - "Young researcher award 2014".

* Corresponding author at: Bilkent University, Psychology Department, 06800

Bilkent, Ankara, Turkey. Tel.: +1 206525 4479; fax: +1 5124715935.

E-mail address: davidlewis@utexas.edu (D.M.G. Lewis).
}

chological processes that would have motivated these behaviors, and (3) conducts empirical tests of these hypothesized design features. Personality psychology has historically operated outside of such a predictive theoretical framework, focusing more on the statistical structure of personality differences than on the origins of personality variation (Buss, 1987).

An exploration of the Five-Factor Model (FFM, Costa \& McCrae, 1992) provides an illustration of how an evolutionary perspective may be fruitfully applied to personality psychology. High levels of extraversion describe a suite of cognitions, emotions, and behaviors hypothesized to promote mating (MacDonald, 2006) both directly (e.g., by engaging potential mates) and indirectly by facilitating the formation of friendships and alliances that enable upward social mobility (Denissen, 2008; Nettle, 2006). High levels of agreeableness may promote successful group coordination and the cultivation of interpersonal bonds by motivating individuals to prize cooperation and group goals (Denissen, 2008). High levels of conscientiousness are hypothesized to promote good health and longevity through self-discipline and determination (Denissen, 2008; Nettle, 2006). Neuroticism is hypothesized to serve protective functions; worry and anxiety motivate behaviors that protect limited social opportunities and avoid ecological dangers (Denissen, 2008; Lewis, 2014; Nettle, 2006). High levels of Openness may also facilitate short-term mating success (Haselton \& Miller, 2006) by means of a proclivity for adventurousness and a desire for variety, exploration, and new experiences (Goldberg \& et al., 2006). 
These personality strategies can also carry costs. The sensationseeking associated with extraversion can lead to traumatic injury (Field \& O'Keefe, 2004), and high agreeableness may lead to social exploitation (Judge, Livingston, \& Hurst, 2012). High levels of neuroticism can place unnecessary strain on social relationships (Buss, 1991) and are associated with impaired physical and psychological health (Neeleman, Sytema, \& Wadsworth, 2002). In the currency of survival and reproduction, each point on a personality dimension carries both costs and benefits (DeKay \& Buss, 1992).

An evolutionary condition-dependent model of individual differences posits that species-typical psychological mechanisms process, as input, cues ancestrally predictive of the costs and benefits of alternative personality strategies, and produce, as output, the strategy of greater probabilistic net benefit for the individual (Lewis, 2014; Wolf, van Doorn, Leimar, \& Weissing, 2007).

\subsection{Adaptive individual differences in Openness}

Ancestrally, successful short-term mating could have yielded valuable reproductive benefits (Schmitt, 2004) for both men and women (see Greiling \& Buss, 2000). A task analysis (Marr, 1982) of the psychological features that facilitate short-term mating points to a suite of attributes are associated with high levels of Openness.

High Openness is characterized by a desire for newness, a preference for variety, and adventurousness (Goldberg et al., 2006). These psychological characteristics bear a striking resemblance to the output of short-term mating mechanisms (Buss, 2012). This parallel between hallmarks of Openness and design features of short-term mating points toward the possibility that evolved psychological mechanisms functionally calibrate levels of Openness to regulate short-term mating. If this is true, a key design feature of these psychological mechanisms should be sensitivity to situationand person-based inputs that shift the costs and benefits of pursuing a particular mating opportunity.

\subsubsection{The situation}

1.2.1.1. Mating context. Although the psychological characteristics associated with high levels of Openness may facilitate short-term mating, they do not necessarily promote long-term, committed mating. On this basis, we hypothesized that mating context should be a key input into the proposed Openness-regulating mechanism.

1.2.1.2. The mate's attractiveness. Because physical attractiveness is a putative indicator of genetic quality, the fitness benefits of mating with an attractive individual are typically greater than those of mating with an unattractive individual (Gangestad \& Simpson, 2000). We therefore hypothesized that a mate's attractiveness would be a key input into the proposed mechanism.

\subsubsection{The individual}

1.2.2.1. The individual's attractiveness, mating strategy, and sex. Because an individual's attractiveness enhances his or her mate value (Buss, 2003), unattractive individuals experience a more adverse mating environment, whereas attractive individuals secure partners with greater ease (Buss \& Barnes, 1986). Less attractive individuals thus may stand to gain comparatively more from new mating opportunities.

Moreover, because physical attractiveness is an important component of mate value, attractive individuals may be better able to implement their preferred mating strategy. Relative to women, men are more inclined, on average, toward short-term mating (Buss, 2012; Buss \& Schmitt, 1993), and men who possess attributes associated with increased attractiveness (e.g., symmetry) have more affair and lifetime sex partners (Gangestad \& Simpson, 2000) and allocate fewer resources to parenting than do their less attractive counterparts (Buss, 2012). Similarly, the mate preferences of attractive women suggest that they are better able to implement a long-term mating strategy: whereas less attractive women may make trade-offs for qualities desired in mates, more attractive women seek morphological indicators of genetic quality in addition to commitment, financial provisioning, and parental investment (Buss \& Shackelford, 2008).

\subsubsection{The (input) power of the situation $x$ person interaction}

Our reasoning about the hypothesized Openness-calibrating mechanism suggested five inputs: mating context (short-term vs. long-term) and the mate's attractiveness, as well as the individual's own attractiveness, mating strategy, and sex. However, this analysis did not simply generate main effects hypotheses. The proposed function of the hypothesized mechanism is to calibrate Openness to facilitate the pursuit of valuable short-term mating opportunities and deter costly mating decisions. Because it is the interaction between these situation- and person-based differences that influences the net costs and benefits of Openness, a key design feature of the mechanism should be its calibration of Openness as a function of the interactions between these cues.

This overarching proposal generated a suite of hypotheses. First, we hypothesized that the effect of mating opportunities on individuals' Openness depends on the interaction between mating context (short-term vs. long-term) and the mate's attractiveness (Hypothesis 1). Because high Openness would not necessarily facilitate the pursuit of committed relationships, we would not expect long-term mating opportunities to affect Openness levels (Hypothesis 2). On the other hand, because Openness may influence pursuit or avoidance of short-term mating, we hypothesized that individuals' Openness would shift in response to short-term mating opportunities. Because short-term mating generally would have been more beneficial with attractive rather than unattractive mates, we hypothesized that individuals would exhibit more positive shifts in Openness in response to short-term mating opportunities with more attractive individuals (Hypothesis 3 ).

Short-term mating would have represented a valuable opportunity in some contexts, but under other circumstances, it would have been injudicious. Short-term mating may have been less valuable (1) for individuals readily able to secure mating opportunities (e.g., by virtue of their attractiveness), (2) for women compared to men, and (3) for individuals less oriented toward short-term mating (e.g., more oriented toward long-term mating; see Jackson \& Kirkpatrick, 2007).

Short-term mating with someone of average attractiveness would generally have been less valuable for individuals of high attractiveness, who can more readily secure mating opportunities with high mate-value partners (Buss \& Barnes, 1986). Short-term mating also would have been less beneficial, on average, for women than for men-in particular for attractive women who are well positioned to implement a preferred long-term mating strategy. Casual mating with a partner of low mate value would have been especially costly for these women, who unlike their male counterparts, could have been impregnated, incurred reputational damage, and thereby impaired their ability to successfully pursue a long-term mating strategy (see Buss \& Schmitt, 1993). On this basis, we hypothesized that in response to the opportunity to short-term mate with a partner of average attractiveness, individuals' Openness will be calibrated as a function of the interaction between their attractiveness, mating strategy, and sex (Hypothesis 4).

1.2.3.1. Men. Highly attractive men are more desirable as shortterm mates (e.g., Pillsworth \& Haselton, 2006). As a consequence, they have a larger pool of potential short-term mates, and can afford to be more discriminating about their short-term mates. We therefore hypothesized that, relative to less attractive men, more attractive men would exhibit a less positive shift in Openness 
in response to a short-term opportunity with a mate of average attractiveness (Hypothesis 5). We were unable to specify on a priori grounds whether men overall would exhibit a positive shift in Openness in response to this opportunity because there are both costs and benefits to short-term mating with an individual of average attractiveness. Rather, our reasoning pointed toward differential effects as a function of men's attractiveness (i.e., less up-regulation or greater down-regulation of Openness among more attractive men).

For more attractive men who are less oriented toward shortterm mating, short-term mating with a woman of average attractiveness neither aligns with their preferred mating strategy nor offers an opportunity to mate with someone of comparable mate value to their typical partners. We therefore hypothesized that more attractive men with a weaker orientation toward short-term mating would be maximally distant from unattractive men in their responses to the prospect of short-term mating with a woman of average attractiveness (Hypothesis 6).

The opportunity to short-term mate with a highly attractive woman, on the other hand, would likely have represented a rare opportunity for most ancestral men. We therefore advanced the hypothesis that, unlike men's differential Openness-shifts in response to a short-term opportunity with a woman of average attractiveness, men's responses to a short-term opportunity with a highly attractive woman would be independent of their attractiveness and preferred mating strategy (Hypothesis 7).

1.2.3.2. Women. Ancestral women generally would have reaped few fitness benefits from short-term mating in unpropitious circumstances. The costs of uncommitted mating would have been exacerbated if the woman's mate were of low mate value; the costs of forgoing commitment would not have been offset by direct genetic benefits for her offspring. We therefore hypothesized that women would show down-regulated Openness in response to the prospect of short-term mating with a man of average attractiveness (Hypothesis 8). Moreover, because such a prospect neither offers the opportunity to mate with a high mate-value partner nor aligns with a beneficial long-term mating strategy, we hypothesized that this effect would be independent of women's attractiveness and mating strategy (Hypothesis 9).

By contrast, short-term mating with a highly attractive man could have yielded direct fitness benefits that could have partially offset the costs of forgoing commitment. We therefore hypothesized that women would exhibit less negative shifts in Openness in response to a short-term opportunity with a highly attractive man (Hypothesis 10).

Although short-term mating with a highly attractive man could have yielded such benefits, not all women would have had to forgo men's commitment in order to obtain these benefits. Attractive women may be able to secure attractive mates and their commitment (Buss \& Shackelford, 2008). We therefore hypothesized that women's shifts in Openness in response to a short-term opportunity with a highly attractive man would be inversely related to their own attractiveness (Hypothesis 11).

To test these hypotheses, we employed an experimental design in which participants were exposed to scenarios describing different mating opportunities with individuals varying in physical attractiveness.

\section{Method}

\subsection{Participants}

Ninety-five men $\left(M_{\text {age }}=23.68\right.$ years, $\left.S D_{\text {age }}=8.10\right)$ and 244 women $\left(M_{\mathrm{age}}=23.21\right.$ years, $\left.S D_{\text {age }}=7.47\right)$ were recruited from social media websites.

\subsection{Materials}

\subsubsection{Scenarios}

Vignettes written in the second person described mating opportunities differing in duration. The short-term mating vignette described a scenario in which the participant receives an unexpected call from a potential mate whom the participant may not see again in the future. The person invites the participant to spend the night, highlighting that this might be the last night they spend together. The long-term mating vignette described a scenario in which the participant has met someone whom they can see as a potential long-term mate, with whom they have discussed future plans, and whom they will likely see again.

\subsubsection{Mates}

The vignettes were paired with photographs of potential mates of differing levels of attractiveness. The photographs were selected to create experimental conditions that depicted a potential mate that was of average or high attractiveness. Independent ratings from 10 research assistants confirmed that the four individuals selected (two of each sex) were indeed average (male: $M=2.4$, $S D=0.7$, female: $M=2.7, S D=0.8$ ) or high in attractiveness (male: $M=4.4, S D=0.7$, female: $M=4.1, S D=0.6 ; 1=$ not at all attractive, 5 = extremely attractive).

These photographs were paired with the mating vignettes to create three experimental conditions: (1) a short-term mating opportunity with an individual of average attractiveness, (2) a short-term mating opportunity with an individual of high attractiveness, and (3) a long-term mating opportunity with an individual of high attractiveness. We also included a control condition that paralleled the long-term mating opportunity. However, no photograph was presented and the sex of the acquaintance was not specified. Consequently, there was no suggestion of a mating opportunity.

\subsubsection{Physical attractiveness}

We assessed participants' attractiveness with the International Personality Item Pool physical attractiveness scale (Goldberg et al., 2006).

\subsubsection{Mating strategy}

We operationalized mating strategy with the revised Sociosexual Orientation Inventory (SOI-R; Penke \& Asendorpf, 2008), which assesses an individual's behavioral history of, attitudes toward, and desire for uncommitted sex. The SOI-R's nine items can be summed to form a composite score, with higher scores reflecting a stronger short-term mating strategy.

\subsubsection{Openness to experience}

Because we employed a within-subjects design in which participants provided both pre- and post-reports of their Openness, we needed an Openness measure that could be concealed within a larger questionnaire. We selected the Ten-Item Personality Inventory (TIPI; Gosling, Rentfrow, \& Swann, 2003), a brief, reliable measure of the FFM that exhibits strong psychometric properties, including convergent validity with lengthier personality measures (Gosling et al., 2003).

\subsection{Procedure}

Participants completed study measures online. As part of a larger study on individual differences, participants first completed a questionnaire containing the SOI-R and TIPI. Participants were then randomly assigned to one of the three experimental conditions or the control condition, and asked to consider what they would think, feel, say, and do in response to the scenario. 
Participants then engaged in a distracter task that took approximately $10-15 \mathrm{~min}$ to complete. Upon completion, participants were again presented with a questionnaire within which the TIPI and physical attractiveness scale were embedded.

\section{Results}

\subsection{Statistical analysis}

Because we predicted differential shifts in Openness in response to the mating scenarios, our focal outcome was the difference between participants' pre- and post-Openness scores. We used this difference score as the outcome variable in a series of analyses examining (1) the overall effects of the mating scenarios and (2) moderation of these effects by individual differences shifting the cost-benefit tradeoffs of Openness.

\subsection{Differential effects of mating opportunity}

Consistent with Hypothesis 1, a one-way ANOVA indicated that shifts in Openness varied as a function of experimental condition, capturing the key interaction between mating context and the mate's attractiveness $F(3,335)=4.33, p<.01$ (Fig. 1). Consistent with Hypothesis 2, individuals' Openness did not shift in response to a long-term mating opportunity $[M=.02, S E=.07, t(88)=0.34$, $n s]$. By contrast, short-term mating opportunities exerted differential effects on individuals' Openness. Consistent with Hypothesis 3 , pairwise comparisons indicated that, relative to a short-term mating opportunity with an individual of high attractiveness, Openness levels were down-regulated in response to a short-term opportunity with an individual of average attractiveness [Difference between means $=-.33, S E=.10, p<.01]$. Individuals in the control condition did not exhibit any shifts in Openness $[M=.11, S E=.09$, $t(79)=1.27, n s]$.

\subsection{An average short-term mate}

Openness was down-regulated $(M=-.22, S E=.07)$ in response to a short-term mating opportunity with an individual of average attractiveness, $t(80)=-3.29, p=.001$. In support of Hypothesis 4 ,
Table 1

Regression model predicting shifts in Openness in response to a short-term mating opportunity with an individual of average attractiveness.

\begin{tabular}{llll}
\hline & $B$ & $S E$ & $\beta$ \\
\hline Individual differences & & & \\
$\quad$ Sex & 5.81 & 1.97 & $4.03^{* *}$ \\
$\quad$ Sociosexual orientation & .02 & .06 & .30 \\
$\quad$ Attractiveness & .02 & .03 & .24 \\
$\quad$ Two-way interactions & & & \\
$\quad$ Sex x SOI-R & -.28 & .12 & $-3.44^{*}$ \\
$\quad$ SOI-R x attractiveness & .00 & .00 & -.26 \\
$\quad$ Sex x attractiveness & -.23 & .07 & $-4.66^{* *}$ \\
$\quad$ Three-way interaction & & & \\
$\quad$ Sex x SOI-R x attractiveness & .01 & .00 & $3.90^{*}$ \\
\hline$*{ }^{* *} p<.05$. & & & \\
$p<.01$. & & &
\end{tabular}

regression analyses indicated that this effect depended on the interaction between participants' sociosexual orientation, attractiveness, and sex, $\beta=3.90, p=.02$ (Table 1 ).

\subsubsection{Men}

Figure 2 shows that men's attractiveness was inversely related to their Openness-shifts in response to a short-term mating opportunity with a woman of average attractiveness. However, isolating this subset of the sample (only 17 men) yielded a test value that did not reach statistical significance despite the medium-to-large effect size in the direction expected under Hypothesis 5, $r(15)=-.34, d=.73, p=.09$.

Similarly, Fig. 2 displays that more attractive men who are less oriented toward short-term mating exhibited greater decreases in Openness than those more oriented toward short-term mating. However, with only 13 degrees of freedom, the large interactive effect between men's attractiveness and mating strategy $(d=1.04)$ did not reach statistical significance $(p=.09)$. We thus could not establish support for Hypothesis 6.

\subsubsection{Women}

In support of Hypothesis 8, women down-regulated their Openness in response to the prospect of short-term mating with a man

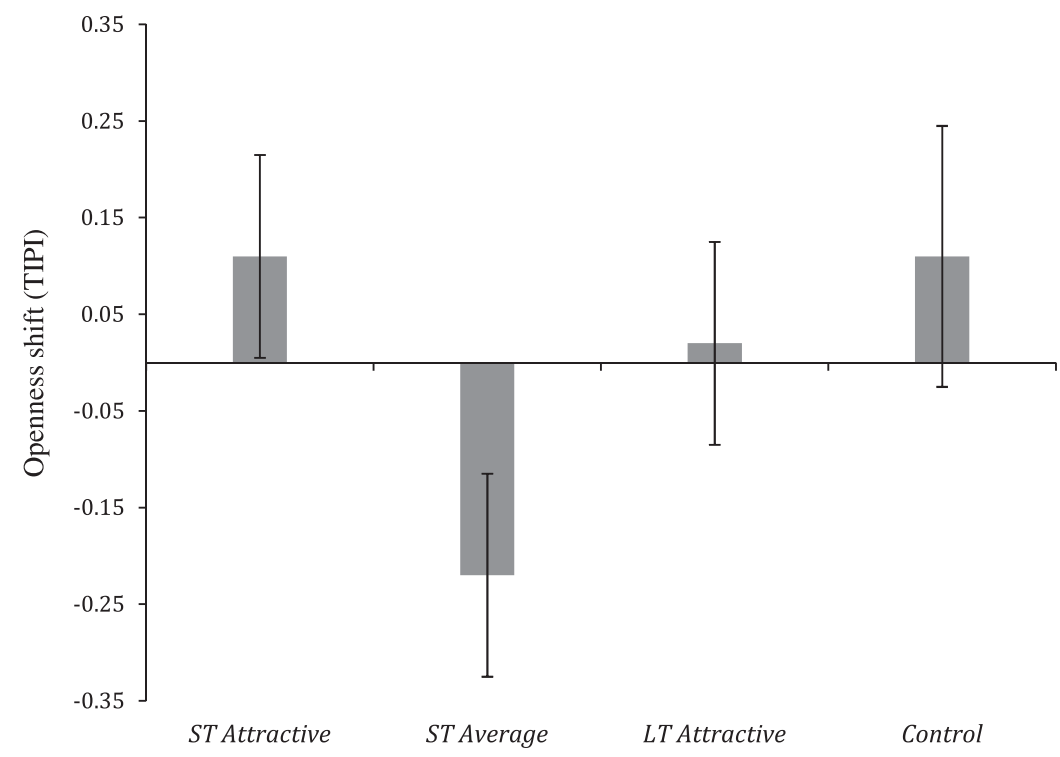

Note. Error bars represent $\pm 1.5 S E$

Fig. 1. Shifts in Openness to Experience as a function of mating opportunity. 


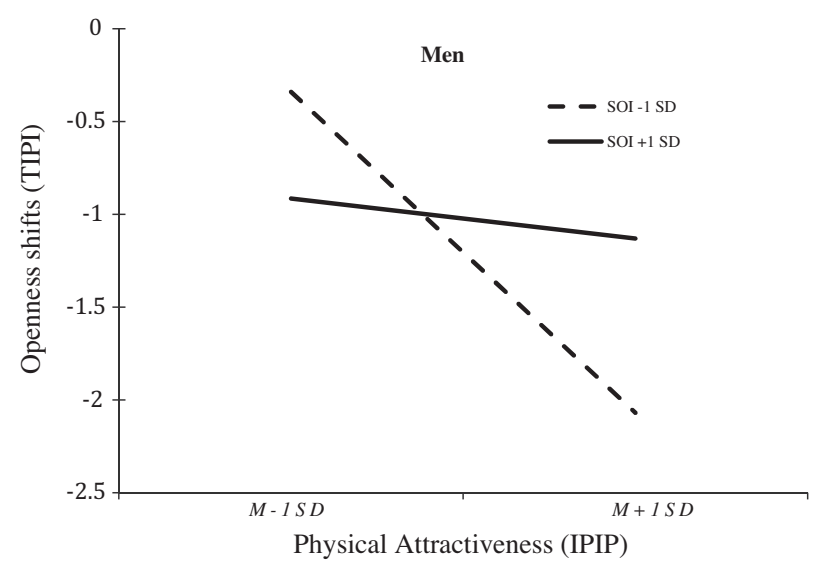

Fig. 2. Men's shifts in Openness in response to a short-term mating opportunity with a woman of average attractiveness as a function of the men's own attractiveness and mating strategy. Lines represent model-generated predicted values.

of average attractiveness, $M=-.13, S E=.06, t(63)=-2.05, p<.05$. Consistent with Hypothesis 9, this effect did not depend on women's mating strategy $[r(62)=.10, n s]$ or attractiveness $[r(62)=.19, n s]$.

\subsection{Attractive short-term opportunity}

There was no overall increase in Openness at the prospect of short-term mating with an individual of high attractiveness, $M=.11, S E=.07, t(88)=1.57, p=.12$. However, regression analyses indicated a significant interaction between individuals' attractiveness and sex in predicting Openness-shifts in response to this opportunity, $\beta=.91, p=.02$.

Sex-specific analyses revealed that, consistent with Hypothesis 11 , less attractive women exhibited greater increases in Openness at the opportunity to short-term mate with a highly attractive man, $r(62)=-.25, p<.05$ (Fig. 3). By contrast, men's shifts in response to this rare opportunity were independent of their attractiveness $[r(23)=.25, p=.24]$ and mating strategy $[r(23)=-.06$, $p=.76]$, consistent with Hypothesis 7 .

Women did not exhibit an overall increase in Openness in response to a short-term mating opportunity with a man of high attractiveness, $M=.10, S E=.08, t(63)=1.33, p=.19$. However, consistent with Hypothesis 10, women's shifts were more positive than those in response to the same opportunity with a man of average attractiveness, Difference between means $=-.23$, $S E=.11, t(126)=-2.32, p=.02$.

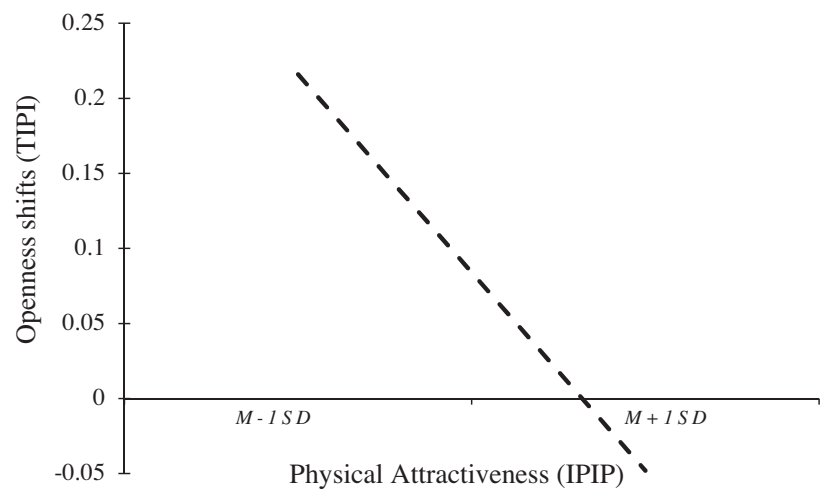

Fig. 3. Women's shifts in Openness in response to a short-term mating opportunity with a highly attractive man as a function of the women's own physical attractiveness. Line represents model-generated predicted values.

\subsection{Discriminant validity}

The current findings exhibited several forms of discriminant validity. First, as reported above, participants did not exhibit any Openness-shifts in the control or long-term mating conditions. Second, the effects of experimental condition were specific to Openness; there was no effect of mating opportunity on Neuroti$\operatorname{cism}[F(3,335)=0.40, n s]$, Extraversion $[F(3,335)=0.66, n s]$, Conscientiousness $[F(3,335)=1.02, n s]$, or Agreeableness $[F(3,335)=$ $0.12, n s]$.

\section{Discussion}

The current results provide the first evidence that (1) Openness to Experience is calibrated in response to short-term mating opportunities, and (2) Openness-calibrating mechanisms are sensitive to situational and individual variables that shift the costs and benefits of such opportunities.

On average, participants' Openness did not increase in response to the short-term mating opportunity with a mate of high attractiveness. However, the interaction between participants' attractiveness and sex in predicting their Openness-shifts in response to this scenario reveals a nuanced, systematic pattern of individual differences.

\subsection{Women}

These findings appear to partly reflect the shunning of such prospects by attractive women. Research suggests that more attractive women are able to obtain high quality men as long-term mates (Buss \& Shackelford, 2008). For attractive women, not experiencing increased Openness may facilitate avoidance of such short-term mating situations in favor of long-term mating opportunities that better accord with their preferred mating strategy.

Less attractive women, by contrast, may not be able to secure long-term investment from high mate-value men (e.g., Buss, 2003). Consequently, less attractive women may face a trade-off between their mate's investment and mate value; they may pursue long-term mating with men of comparatively lower mate value, or forgo men's investment and pursue short-term mating with men of comparatively higher value. Men's mating psychology suggests that the latter strategy may result in increased mating opportunities for less attractive women; men's minimum standard for attractiveness in short-term mates is substantially lower than their minimum standard for long-term mates (Kenrick, Groth, Trost, \& Sadalla, 1993).

If a less attractive woman has the opportunity to short-term mate with a high mate-value man, the direct benefits she could obtain may outweigh the costs of forgoing a lower mate-value man's investment. The net benefits of this strategy will depend on the mate value of the long-term mate that the woman could instead secure. When the benefits of short-term mating with a man of high mate value exceed the costs of forgoing a lower mate-value man's commitment, less attractive women may be more willing to pursue short-term mating.

In sum, attractive women may be able to secure both mate value and commitment, but less attractive women may have to engage in a strategic tradeoff between these two qualities. This reasoning suggests that less attractive women may be more likely to experience activation of their short-term mating psychology. The current finding of an inverse relationship between women's attractiveness and their Openness-shifts in response to a shortterm mating opportunity with an attractive man is consistent with this hypothesis. Moreover, it may help resolve a puzzle in the extant literature. 
Although the current study points toward an inverse relationship between women's attractiveness and the activation of their short-term mating psychology, some previous research appears to document a positive relationship. Clark (2004), for example, found a positive correlation between women's attractiveness and their scores on an older version of the SOI. Other studies have demonstrated a positive relationship between women's attractiveness and their number of lifetime sex partners or age at first sex (e.g., Hughes, Dispenza, \& Gallup, 2004; Rhodes, Simmons, \& Peters, 2005; Wiederman \& Hurst, 1998).

More recent research, however, has suggested that these findings may be driven entirely by a correlation between women's attractiveness and history of sexual behavior-a relationship that does not necessarily reflect greater activation of short-term mating psychology (Al-Shawaf, Lewis, \& Buss, 2014). Rather, physically attractive women may accumulate a larger number of sexual partners (and therefore score higher on sexual behavior indices) simply because they have a larger pool of eager suitors, and therefore have a greater number of opportunities to mate with high mate value men. Consistent with this interpretation, more fine-grained analyses reveal no positive association between women's attractiveness and their attitudes toward or desire for short-term mating (AlShawaf et al., 2014). In light of these analyses and the current finding of an inverse relationship between women's attractiveness and their Openness-shifts in response to a short-term mating opportunity with an attractive man, we suggest that more attractive women may have a higher threshold for short-term mating activation. Future research should further investigate this hypothesis to better reconcile the apparent discrepancies between the psychology- and behavioral history-focused literature.

\subsection{Men}

By contrast, men's Openness-shifts in response to a short-term mating opportunity with a woman of high attractiveness did not differ as a function of their own attractiveness or mating strategy. This finding is consistent with the direct fitness benefits that ancestral men would have reaped by short-term mating with a highly attractive woman (Buss, 2003; Symons, 1979) - an effect that may be powerful enough to nullify the impact of individual differences in preferred mating strategy.

The finding that men's Openness shifted downwards in response to a short-term mating opportunity (with a woman of average attractiveness) might seem to contradict evolutionary expectations. However, a nuanced understanding of evolutionary psychological theory reveals how this downward shift is not inconsistent with either theoretical expectations or previous empirical work.

In their seminal paper, Buss and Schmitt (1993) explain that short-term and long-term mating each carry potential costs and benefits, and that both sexes have evolved the capacity to pursue either strategy under certain conditions linked to these costs and benefits. Gangestad and Simpson (2000) echo these ideas; men and women possess conditional mating strategies that enable them to pursue either short-term or long-term mating, including avoiding short-term mating when such a strategy is disadvantageous.

Short-term mating carries greater potential costs for women than for men (Symons, 1979; Trivers, 1972). Consequently, men are more inclined than women to pursue short-term mating (Buss \& Schmitt, 1993). However, this does not imply that men possess an unconditional preference for short-term mating. The hypothesis is that of an on-average sex difference in the desire for short-term mating.

Indeed, relative to women, men are more likely to accept a stranger's invitation to casual sex (Clark \& Hatfield, 1989), have more positive attitudes toward short-term mating (Oliver \& Hyde, 1993), and have lower standards for short-term mates
(Kenrick, Sadalla, Groth, \& Trost, 1990). However, all of these findings reflect a sex difference: men, relative to women, are more oriented toward short-term mating.

Neither theory nor previous research points toward men having an unconditional preference for short-term mating. For example, Kenrick et al. $(1990,1993)$ demonstrate that men have lower standards for short-term mates, but they have also repeatedly found that the minimum attractiveness that men will accept in a shortterm mate is nonetheless above average. According to their research, a woman in the 60th percentile of attractiveness still falls below a man's minimum threshold for a one-night stand (Kenrick et al., 1993). The current finding that men's Openness decreases at the prospect of short-term mating with a woman of average attractiveness is thus less surprising than it may first appear. Rather, it is consistent with evolutionary theorizing, existing empirical findings, and the hypothesis that psychological adaptations down-regulate Openness to deter pursuit of injudicious mating.

\subsection{Limitations $\mathcal{E}$ future directions}

The TIPI's concision was a key aspect of the current study's design, but is not designed for facet-level analyses (Gosling et al., 2003). Future research could profitably examine which facets of Openness shift in response to short-term mating opportunities. Future research could also benefit from a more direct measure of long-term mating orientation. The SOI-R indexes short-term mating psychology and behavior, but short- and long-term mating may reflect distinct dimensions of individual differences, rather than opposite poles of a single dimension (Jackson \& Kirkpatrick, 2007).

To test the current study's central hypothesis that psychological mechanisms calibrate individuals' Openness levels in response to short-term mating opportunities, we exposed participants to different short-term mating opportunities. We also exposed participants to a long-term mating condition that paralleled one of the short-term mating conditions in order to test the specificity of Openness-shifts to short-term mating contexts. Although this long-term condition enabled preliminary tests of this specificity, it nonetheless would have been advantageous to include a fifth condition that described a long-term mating opportunity with an individual of average attractiveness. If the hypothesized, Opennesscalibrating mechanism's effects are specific to short-term mating, then - unlike the significant shifts in Openness that participants exhibited in response to the prospect of short-term mating with an individual of average attractiveness - individuals' Openness would not be expected to shift in response to a long-term mating opportunity with an individual of average attractiveness. This remains an open question for future research.

Participants' relationship status may also be a key variable influencing the costs and benefits of Openness to short-term mating. Extra-pair mating jeopardizes mated individuals' exclusive access to their mates (Buss, 2003) and puts them at risk of retaliation by their mates, mates' kin, or mates' allies (Burchell \& Ward, 2011; Buss \& Duntley, 2011; Greiling \& Buss, 2000). Because these costs are nonexistent for unmated individuals, but the benefits of short-term mating should be at least as great, unmated individuals likely derive greater net benefits from up-regulating their Openness in response to short-term mating opportunities. Sample limitations (e.g., four mated men in one experimental condition, and five in another) prevent the current study from directly addressing this issue, but future studies should investigate this hypothesis.

Experimental methodology carries considerable benefits, but also suffers from limitations. First, individuals' mate value influences their ability to attract desirable mates and implement their preferred mating strategy (e.g., Buss \& Shackelford, 2008). Random assignment may have resulted in discrepancies (1) between the 
attractiveness of the mates participants can typically obtain and that of the hypothetical mate presented, and (2) between participants' preferred mating strategy and the mating context presented. Second, Openness-calibrating mechanisms must produce behavioral output in order to solve the adaptive challenges they are hypothesized to solve. Future research should study Opennesscalibration with indices more proximate to real-life mating behavior such as receptivity to date solicitation or approach behavior in naturalistic settings.

\subsubsection{Isolating personality trait variation}

One challenge facing the hypothesis that evolved psychological mechanisms calibrate personality trait levels (Lukaszewski, 2013; Tooby \& Cosmides, 1990) is trait covariation: if each personality trait is calibrated by a distinct mechanism, then why do trait levels covary?

One possibility is that different personality dimensions are calibrated by distinct mechanisms, but based on shared inputs (Buss, 2009; Lukaszewski, 2013; Tooby \& Cosmides, 1990). For example, individual differences in mate value, which shift the cost-benefit tradeoffs of both neuroticism and extraversion, should lead to covarying individual differences on these dimensions. Extant data are consistent with this proposal (Lukaszewski, 2013), but cannot rule out the possibility that covarying traits reflect the operation of a single, latent factor that calibrates multiple dimensions of personality simultaneously (e.g., Rushton \& Irwing, 2008).

The view that each personality dimension is calibrated by a distinct mechanism suggests the following. If a cue is linked to an adaptive challenge that a particular personality trait evolved to solve - and not linked to any adaptive challenges that other personality traits evolved to solve - then individual differences in exposure to that cue should only calibrate that single personality dimension (Lewis, 2014). The findings reported here offer preliminary evidence in support of this view, as short-term mating opportunities calibrated Openness but had no effect on any of the other four personality dimensions of the FFM. This key finding offers preliminary evidence of the discriminant validity of our manipulation, as well as the first empirical evidence of an input that calibrates a single personality dimension in isolation.

\subsection{2. "Trait" flexibility?}

The temporal "snapshots" of Openness-shifts reported here point to an important direction for future research. There are costs associated with maintaining a flexible behavioral repertoire (Dall, Houston, \& McNamara, 2004). However, because changes in situational and individual variables across the lifespan shift the costbenefit payoffs of alternative personality strategies, there are also costs associated with "crystallizing" personality too firmly (Buss, 2000; Buss \& Penke, 2014).

The cost-benefit tradeoffs of personality crystallization and flexibility may have led to the evolution of psychological adaptations that fix trait levels within a certain range during development, but that can subsequently produce adaptive local shifts as the costs and benefits of alternative strategies change during the lifespan. The experimentally induced shifts in Openness reported here provide initial evidence of flexible personality calibration in response to shifting cost-benefit payoffs of alternative personality strategies, but evidence of "trait-level" shifts awaits longitudinal studies (see Lewis, 2014).

\subsection{Conclusions}

The current findings are the first to suggest that Openness to Experience may systematically shift to facilitate or deter short-term mating. They are also the first to demonstrate an interaction between three individual difference variables - mating strategy, attractiveness, and sex - in calibrating personality. The current research offers an empirical step toward a more deeply explanatory framework for personality variation, guided by the evolutionary psychological heuristic of condition- and state-dependent personality calibration.

\section{References}

Al-Shawaf, L., Lewis, D. M. G., \& Buss, D. M. (2014). Disgust and mating strategy. Evolution \& Human Behavior.

Burchell, J. L., \& Ward, J. (2011). Sex drive, attachment style, relationship status and previous infidelity as predictors of sex differences in romantic jealousy. Personality and Individual Differences, 51(5), 657-661.

Buss, D. M. (1987). Selection, evocation, and manipulation. Journal of Personality and Social Psychology, 53(6), 1214-1221.

Buss, D. M. (1991). Conflict in married couples: Personality predictors of anger and upset. Journal of Personality, 59(4), 663-703.

Buss, D. M. (1995). Evolutionary psychology: A new paradigm for psychological science. Psychological Inquiry, 6, 1-30.

Buss, D. M. (2000). The dangerous passion: Why jealousy is as necessary as love and sex. New York: The Free Press.

Buss, D. M. (2003). The evolution of desire: Strategies of human mating (Rev. ed.). New York: Basic Books.

Buss, D. M. (2009). How can evolutionary psychology successfully explain personality and individual differences? Perspectives on Psychological Science, 4(4), 366.

Buss, D. M. (2012). Evolutionary psychology: The new science of the mind (4th ed.). Boston: Allyn \& Bacon.

Buss, D. M., \& Barnes, M. (1986). Preferences in human mate selection. Journal of Personality and Social Psychology, 50(3), 559-570. http://dx.doi.org/10.1037/ 0022-3514.50.3.559.

Buss, D. M., \& Duntley, J. D. (2011). The evolution of intimate partner violence. Aggression and Violent Behavior, 16(5), 411-419.

Buss, D. M., \& Penke, L. (2014). Evolutionary personality psychology. In R. Larsen \& L. Cooper (Eds.), The APA handbook of personality and social psychology, volume 4: Personality processes and individual differences. Washington, D.C: APA Press.

Buss, D. M., \& Schmitt, D. P. (1993). Sexual strategies theory: An evolutionary perspective on human mating. Psychological Review, 100(2), 204-232.

Buss, D. M., \& Shackelford, T. K. (2008). Attractive women want it all: Good genes, economic investment, parenting proclivities, and emotional commitment. Evolutionary Psychology, 6, 134-146.

Clark, A. P. (2004). Self-perceived attractiveness and masculinization predict women's sociosexuality. Evolution and Human Behavior, 25(2), 113-124.

Clark, R. D., \& Hatfield, E. (1989). Gender differences in receptivity to sexual offers. Journal of Psychology and Human Sexuality, 2, 39-55.

Costa, P. T. \& McCrae, R. R. (1992). Revised NEO personality inventory (NEO PI-R) and NEO five-factor inventory (NEO-FFI). Odessa, FL: Psychological Assessment Resources.

Dall, S. R. X., Houston, A., \& McNamara, J. (2004). The behavioural ecology of personality: Consistent individual differences from an adaptive perspective. Ecology Letters, 7(8), 734-739.

DeKay, W. T., \& Buss, D. M. (1992). Human nature, individual differences, and the importance of context: Perspectives from evolutionary psychology. Current Directions in Psychological Science, 1, 184-189.

Denissen, J. J. A. (2008). Motivational individual reaction norms underlying the FiveFactor model of personality: First steps towards a theory-based conceptual framework. Journal of Research in Personality, 42(5), 1285-1302.

Field, C. A., \& O'Keefe, G. (2004). Behavioral and psychological risk factors for traumatic injury. Journal of Emergency Medicine, 26(1), 27-35. http://dx.doi.org/ 10.1016/j.jemermed.2003.04.004.

Gangestad, S. W., \& Simpson, J. A. (2000). The evolution of human mating: Tradeoffs and strategic pluralism. Behavioral and Brain Sciences, 23, 573-587. http:// dx.doi.org/10.1017/S0140525X0000337X

Goldberg, L. R. et al. (2006). The international personality item pool and the future of public-domain personality measures. Journal of Research in Personality, 40(1), 84-96. http://dx.doi.org/10.1016/j.jrp.2005.08.007.

Gosling, S. D., Rentfrow, P. J., \& Swann, W. B. (2003). A very brief measure of the BigFive personality domains. Journal of Research in Personality, 37(6), 504-528. http://dx.doi.org/10.1016/S0092-6566(03)00046-1.

Greiling, H., \& Buss, D. M. (2000). Women's sexual strategies: The hidden dimension of extra-pair mating. Personality and Individual Differences, 28, 929-963.

Haselton, M. G., \& Miller, G. F. (2006). Women's fertility across the cycle increases the short-term attractiveness of creative intelligence. Human Nature, 17(1) 50-73. http://dx doi.org/10.1007/s12110-006-1020-0.

Hughes, S. M., Dispenza, F., \& Gallup, G. G. Jr., (2004). Ratings of voice attractiveness predict sexual behavior and body configuration. Evolution and Human Behavior, 25(5), 295-304.

Jackson, J. J., \& Kirkpatrick, L. A. (2007). The structure and measurement of human mating strategies: Toward a multidimensional model of sociosexuality. Evolution and Human Behavior, 28(6), 382-391.

Judge, T. A., Livingston, B. A., \& Hurst, C. (2012). Do nice guys-and gals-really finish last? The joint effects of sex and agreeableness on income. Journal of Personality and Social Psychology, 102(2), 390-407. 
Kenrick, D. T., Groth, G. E., Trost, M. R., \& Sadalla, E. K. (1993). Integrating evolutionary and social exchange perspectives on relationships: Effects of gender, self-appraisal, and involvement level on mate selection criteria. Journal of Personality and Social Psychology, 58(6), 951-969.

Kenrick, D. T., Sadalla, E. K. Groth, G. E. \& Trost, M. R. (1990). Evolution, traits, and the stages of human courtship: Qualifying the parental investment model. Journal of Personality, 58, 97-116.

Lewis, D. M. G. (2014). Evolved individual differences: Advancing a conditiondependent model of personality. Personality and Individual Differences.

Lukaszewski, A. W. (2013). Testing an adaptationist theory of trait covariation: Relative bargaining power as a common calibrator of an interpersonal syndrome. European Journal of Personality.

MacDonald, K. (2006). Evolution, the five factor model, and levels of personality. Journal of Personality, 63(3), 525-567.

Marr, D. (1982). Vision: A computational investigation into the human representation and processing of visual information. San Francisco: Freeman.

Neeleman, J., Sytema, S., \& Wadsworth, M. (2002). Propensity to psychiatric and somatic ill-health: Evidence from a birth cohort. Psychological Medicine, 32, 793-803. http://dx.doi.org/10.1017/S0033291702005901.

Nettle, D. (2006). The evolution of personality variation in humans and other animals. American Psychologist, 61(6), 622-631. http://dx.doi.org/10.1037/0003066X.61.6.622.

Oliver, M. B., \& Hyde, J. S. (1993). Gender differences in sexuality: A metaanalysis. Psychological Bulletin, 114, 29-51.

Penke, L., \& Asendorpf, J. B. (2008). Beyond global sociosexual orientations: A more differentiated look at sociosexuality and its effects on courtship and romantic relationships. Journal of Personality and Social Psychology, 95(6), 1113-11135.
Pillsworth, E. G., \& Haselton, M. G. (2006). Male sexual attractiveness predicts differential ovulatory shifts in female extra-pair attraction and male mate retention. Evolution \& Human Behavior, 27, 247-258.

Rhodes, G., Simmons, L. W., \& Peters, M. (2005). Attractiveness and sexual behavior: Does attractiveness enhance mating success? Evolutionary E' Human Behavior 26(2), 186-201.

Rushton, J. P., \& Irwing, P. (2008). A general factor of personality (GFP) from two meta-analyses of the Big Five: Digman (1997) and Mount, Barrick, Scullen, and Rounds (2005). Personality and Individual Differences, 45(7), 679-683.

Schmitt, D. P. (2004). The Big Five related to risky sexual behaviour across 10 world regions: Differential personality associations of sexual promiscuity and relationship infidelity. European Journal of Personality, 18, 301-319.

Symons, D. (1979). The evolution of human sexuality. New York: Oxford University Press.

Tooby, J., \& Cosmides, L. (1990). On the universality of human nature and the uniqueness of the individual: The role of genetics and adaptation. Journal of Personality, 58(1), 17-67. http://dx.doi.org/10.1111/j.1467-6494 1990.tb00907.x.

Trivers, R. L. (1972). Parental investment and sexual selection. In B. Campbell (Ed.) Sexual selection and the descent of man (pp. 136-179). Chicago: Aldine.

Wiederman, M. W., \& Hurst, S. R. (1998). Body size, physical attractiveness, and body image among young adult women: Relationships to sexual experience and sexual esteem. Journal of Sex Research, 35(3), 272-281.

Wolf, M., van Doorn, G. S., Leimar, O., \& Weissing, F. J. (2007). Life-history trade-offs favour the evolution of animal personalities. Nature, 447, 581-584. http:// dx.doi.org/10.1038/nature05835. 